\title{
TRANSFORMAÇÕES DO DIREITO
}

\section{Promessa de Compra e Venda de Imóveis}

\author{
Altino P. Soares Pereira \\ Prof. da Faculdade de Direito da \\ Universidade do Paraná.
}

No complexo das relações indispensáveis à coexistência humana, está o edifício jurídico, onde se agazalham o indivíduo e a sociedade, para a consecução de seus fins. Da ordem jurídica assegurada resulta a tranquilidade geral, que é o primeiro fator de progresso.

Mas, essa sociedade que não prescinde do direito para 0 seu desenvolvimento, acarreta, em virtude das transformações por que passa, a modificação do próprio direito, seu mantenedor. Só assim poderemos verificar a exatidão perfeita do brocardo jurídico: "Ubi societas, ibi jus".

A evolução de certos ramos do direito se processa lentamente, enquanto a de outros se dá com celeridade. Os motivos ponderáveis da dicotomia do direito privado o demonstram plenamente.

O direito civil, dada a natureza de seu objeto, é um dos ramos que evolue com lentidão. Esse estado de normalidade, contudo, pode variar desde que surjam fatores decisivos determinando o aparecimento de uma nova disciplina jurídica. $\mathbf{E}$ isto pode dar-se, até, com o sacrifício do sistema adotado e a preterição das exigências da técnica, que cumpririạ observar. 
Êsse fato ocorreu com a promessa de compra e venda, em várias legislações, inclusive a nossa, pela influência de fator econômico cuja desmedida repercussão, nos diferentes setores da atividade, originou modalidade contratual de feição autônoma, sui generis, inconfundível com sua feição antiga de pré-contrato. E a evolução operada, sem a necessária sistematização, acarreta-nos algumas dificuldades não só em seu perfeito entendimento, mas a começar pelo estabelecimento de seu conceito. Êste não pode ser único, uma vez que os aspectos do contrato são vários.

Se, por um lado, apontamos promessas de venda que reunem todos os requisitos jurídicos capazes de lhe garantir uma base econômica conforme às necessidades que lhes deram origem, nos últimos tempos, não é menos certo que existem promessas com possibilidades muito remotas de fiel execução.

Assim, conforme a modalidade em exame e os seus efeitos, teremos o respectivo conceito.

Se se tratar de promessa de contrato, que não onere a coisa prometida à venda e, portanto, sem direito à execução in natura, haverá simples contrato preliminar cujo inadimplemento será sancionado com a condenação ao pagamento de perdas e danos, na forma da lei, e mais o que tiver sido ajustado entre as partes. Dar-se-á, neste caso, a aplicação do princípio "Nemo ad factum praecise cogi potest".

0 mesmo não se verificará, porém, tratando-se da chamada promessa irretratável, sem direito de arrependimento, revestida de tôdas as formalidades para a constituição de um direito real. Neste caso, embora a coisa prometida não fique vinculada ao cumprimento da obrigação, como sucede nos direitos reais de garantia, de qualquer modo suporta o onus de ficar reservada ao promitente-comprador que tem prioridade para sua aquijos efeitos são muito mais extensos que os do precedentemente enunciado. De fato, o seu descumprimento não originará um direito de simples indenização, e, até, bem pelo contrário, culsição. Tais peculiaridades conferem autonomia ao contrato cu- 
minará com a execução in specie, se o inadimplente fôr o promitente-vendedor. $\mathrm{Na}$ verdade, uma vez cumpridas as formalidades legais, entre nós vigentes, êsse contrato originará um direito real de prioridade para a aquisição da propriedade da coisa prometida, que, mais tarde, se converterá no direito de propriedade, quer mediante ato voluntário das partes, quer de uma delas, através da execução coativa.

Muitas figuras intermediárias poderiam referir-se ainda entre êsses dois aspectos, um de feição nìtidamente antiga e outro, como vimos, emergente da atual situação econômica, que ditou preceitos considerados inadiáveis e, porisso, sem qualquer sistematização e em que muito menos se pode falar no rigor técnico.

Entre nós, poderemos lembrar as modalidades seguintes:

a) Os contratos realizados de conformidade com os arts. 1.088, 1.095 e 1.097 do Código Civil em vigor;

b) Os compromissos de compra e venda de imóveis loteados, para a venda em prestações, de que trata o Decreto-Lei n. ${ }^{\circ} 58$, de 10 de dezembro de 1937 , regulamentado pelo Decreto n. ${ }^{\circ} 3.079$, de 15 de setembro de 1938 ;

c) Os contratos, sem cláusula de arrependimento, de compromisso de compra e venda de imóveis não loteados, para pagamento no ato ou em prestações, disciplinados pela Lei $n .{ }^{\circ} 649$, de 11 de março de 1949.

Sem examinar os requisitos e efeitos de cada modalidade aludida, que diversificam de modo considerável, temos em mira apenas assinalar, nesta breve apreciação, o desenvolvimento de suas normas disciplinadoras. Para isso, voltemo-nos apenas para o que diz respeito à execução compulsória.

0 Decreto-Lei n. ${ }^{\circ} 58$ de 1937, já citado, está baseado na Lei Uruguaia n..$^{\circ} 8.733$, de 17 de junho, de 1931. Entretanto, esta última Lei, ao mesmo tempo que dispõe sôbre os efeitos da inscrição da promessa, no Registro competente, estabelece, pa- 
ralelamente, o direito de execução compulsória, uma vez cumpridas as obrigações estipuladas. Eis o teôr de seu art. 15:

"La promesa de enajenación de inmuebles a plazos, desde la inscripción en el Registro, confiere al adquirente, derecho real respecto de cualquer enajenación o gravamen posterior, y, quando se haya pagado o se pague toda la prestación y se hayan cumplido las obligationes estipuladas, le acuerda accion para exigir la transferencia y entrega del bien que constituye el objeto de la prestación. La fecha será la de la inscripción".

Isto não sucede em nosso Decreto-lei, que faz depender a execução compulsória, da existência do aludido registro. Assim dispõe 0 art. 22 , com a redação dada pela Lei $n .^{\circ} 649$, de 11 de março de 1949:

"Os contratos, sem cláusula de arrependimento, de compromisso de compra e venda de imóveis não loteados, cujo preço tenha sido pago no ato da sua constituição, ou deva sê-lo em uma ou mais prestações, desde que inscritos em qualquer tempo, atribuem aos compromissários direito real oponível a terceiros e lhes conferem o direito de adjudicação compulsória, nos têrmos dos arts. 16 desta lei e 346 do Código de Processo Civil". É nosso o grifo.

$\mathrm{E}$ como se isto não bastasse, acrescenta 0 art. 23 do Decreto-Lei mencionado:

"Nenhuma ação ou defesa se admitirá, fundada nos dispositivos desta lei, sem apresentação de documento comprobatório do registro por ela instituido".

Ressaltando, mais uma vez, o valor do registro, chega o legislador a declarar a inviabilidade de qualquer ação, caso o mesmo não tenha sido efetuado. De tal modo, ficou esquecida a possibilidade do exercício de quaisquer ações, mòrmente nos casos em que as promessas de compra e venda não contenham os requisitos para a constituição de direitos reais. De fato, a pro- 
posição contida no art. 23 aludido colide com o preceito do art. 75 de nosso Código Civil, onde se lê: "A todo o direito corresponde uma ação que o assegura". Não podem, realmente, ficar ao desabrigo do direito, desprovidas de ação, as promessas que têm apenas efeitos pessoais. $\mathrm{O}$ art. 23 comentado poderia negar uma ação real, nunca, porém, a que é inerente a qualquer direito e que porisso mesmo integra o conceito de direito subjetivo.

Deixando à margem êsse detalhe de nossa legislação, qual seja a dependência em que ficou a execução compulsória, da existência de um registro, queremos evidenciar que a evolução se processou no sentido de se admitir a execução compulsória, in natura, dos contratos que, antigamente, só pela vontade das partes seriam assim executados.

Não foi pequeno o debate travado, entre os italianos, em tôrno da conhecida decisão da Côrte de Roma, cujo Relator, Faggella, só admitia a execução específica de prestação material conseqüente à determinação psicológica, visto não ser possível a execução coativa da própria vontade.

Mas, sem que se puzessem de acôrdo os pontos de vista externados por Chironi, Ascoli, Coviello, Carnelutti, Chiovenda e tantos outros, à semelhança do que sucedia com exposições de autores estrangeiros, como Pothier, Degenkolb e outros muitos, o interessante é que o velho Código Italiano de 1865 foi, neste particular, modificado pelo de 1942, cujo art. 2.932 estabelece:

"Esecuzione specifica dell'obbligo di concludere un contratto. - Se colui che è obbligato a concludere un contratto non adempie l'obbligazione, l'altra parte, qualora sia possibile e non sia escluso dal titolo, può ottenere una sentenza che produca gli effetti del contratto non concluso.

Se si tratta di contratti che hanno per oggetto il trasferimento della proprietà di una cosa determinata o la costituzione o il trasferimento di un altro diritto (1376), la domanda non può essere accolta se la parte che l'ha proposta non esegue la sua prestazio- 
ne o non ne fa offerta nei modi di legge, a meno che

la prestazione non sea ancora esigibile".

Este diploma admitiu a fungibilidade da prestação assumida, desaparecendo, em conseqüência, o facere incoercível, como objeto do contrato, - que dantes se convertia no pagamento de perdas e danos, em caso de inadimplemento de cláusula contratual, - para que prevalecesse o efeito de uma sentença constitutiva na formação do contrato definitivo.

Alguns escritores têm procurado explicar, entre nós, a coercibilidade das obrigações assumidas nas promessas de compra e venda, declarando que a execução específica, nesse caso, não constitue violência à pessoa, não importa no sacrifício de sua liberdade. Dêsse parecer foi a comissão organizadora do nosso ante-projeto de Código de Obrigações, constituida dos insignes juristas Orozimbo Nonato, Hahnemann Guimarães e Philadelfo Azevedo, êste último já desaparecido, mas sempre lembrado pela obra vultosa que nos legou.

Eis o que consta em um dos tópicos de sua exposição de motivos:

"Nas obrigações de fazer foram destacadas as hipóteses de cumprimento personalíssimo pelo devedor ou de indiferença quanto ao autor da obra a executar (art. 194). Ressalvado o caso de violência à pessoa do devedor, dispôs-se que a sentença suprirá a declaração de vontade, recusada pelo recalcitrante (art. 195), como já consta do decreto-lei sôbre loteamento de imóveis e do próprio Código de Processo".

(D. Oficial União, 10-2-1941, pág. 2655).

0 art. 195 do aludido ante-projeto, assim dispõe:

"Recusada a prestação do fato, pode o credor exigí-la especìficamente, a menos que a execução importe violência à pessoa do devedor.

Parágrafo único. A sentença supre a declaração de vontade, quando, nas obrigações de fazer, o devedor se recusa a prestá-la". 
Inegàvelmente êste preceito de um ante-projeto, que ten tou consolidar idênticas disposições de legislação esparsa, revela o verdadeiro sentido em que se processa a evolução das obrigações de fazer. Dêsse modo, é forçoso concluir que o dispositjvo do art. 879 de nosso Código Civil sofre limitações, não mais se podendo afirmar, irrestritamente, que o descumprimento das obrigações de fazer se converta no ressarcimento de perdas e danos.

Vultosos interêsses de ordem econômica exigiram uma disciplina legal especializada para as inúmeras relações de negócio, no sector imobiliário, que, ao mesmo tempo, concretizasse os anceios das partes contratantes e lhes proporcionasse a maior segurança. É o fator econômico, já assinalado, que provoca, no caso, a transformação do direito. Ninguém ousa ignorar a estreita correlação entre a Economia e o Direito Civil e por essa razão não pode causar estranheza que a evolução dêste seja devida, em muitos casos, aos justos reclamos daquela.

Entretanto, se esta é a realidade em que nos situamos, convém esclarecer que a evolução constatada no setor da promessa de compra e venda, não se deu sem um atrito, sem uma colisão de princípios, enfim, sem o sacrifício de sistemas e da necessária técnica, que lhe deveriam presidir. $\mathrm{E}$ isto se explica pela agravação do problema, dado o volume de transações existente, que precipitou uma legislação apressada e imperfeita.

Inúmeras observações têm sido feitas a êsse respeito. Na Itália, onde o assunto foi amplamente discutido e culminou com a inclusão de novas disposições, em seu Código Civil, admitindo a execução específica das obrigações de fazer, críticas severas vêm se opondo aos rumos seguidos pelo legislador.

O Prof. Salvatore Satta, da Universidade de Gênova, em trabalho recente, sob o título "L'Esecuzione Forzata", in Trattato di Diritto Civile Italiano, sob a direção de Filippo Vassalli, XV - 1, 2. ${ }^{\circ}$, pág. 259-263, do ano de 1954, faz a apreciação do mencionado art. 2.932 do Código Civil Italiano, declarando que o mesmo constitue uma aberração. 0 ilustre mestre de direito não concebe que a execução específica seja simples decorrên- 
cia de uma disposição legal, visto que aquela depende da natureza e do conteúdo da obrigação a ser cumprida.

Assim, depois de ter revelado a inconsistência sistemática do aludido artigo, o que, em seu entender, o próprio legislador reconhece, êle assevera:

"Non crediamo di errare dicendo che, al lume della logica giuridica, questa norma transitoria, e sopratutto la posizione del legislatore di fronte alla esecuzione specifica che essa denuncia, costituisce una aberrazione. Sembra evidente che il legislatore abbia messo l'esecuzione specifica dell'obbligo di contrarre sul piano di un qualunque mezzo di tutela concesso al creditore (ad es., la resiluzione del contratto) e portanto lo abbia visto in funzione di una particolare norma legislativa che lo istituisca, e senza la quale non può sussistere: quando invece è chiaro che l'esecuzione specifica dipende dalla natura e dal contenuto dell'obbligo, cosi che se esso la consente non c'è nessun bisogno di norma che la conceda, se non la consente, nessuma norma può realizare l'impossibile. Vero è che la giurisprudenza senza badare troppo per il sottile dichiarava apertamente che senza una norma ad hoc non poteva riconoscere l'ammissibilità dell'esecuzione (e anzi l'introduzione di tale norma apertamente si augurava); ma è anche vero che gli spiriti più acuti tra coloro che negavano l'ammissibilità, non meno apertamente proclamavano che una simile esecuzione non era possibile nè de jure condito nè de jure condendo; e d'altra parte, non pochi fra i dottori e i pratici, dalla natura del contratto desumevano l'ammissibilità senza bisogno di particolari norme. L'errore del legislatore è del resto in tutto simile a quello che egli commette quando (como si è visto nella relazione) attribuisce un valore istitutivo alla norma dell'art. 2.908, quasi que fosse in suo potere ammettere o escludere la categoria delle sentenze costitutive!" Pág. 260. 
Fixando o justo limite entre o objeto do contrato preliminar e o do definitivo, o autor põe em relêvo a incoercibilidade da obrigação no primeiro contida, que, para êle, não se coaduna com a execução pela forma específica, em caso de inadimplemento, mas sòmente com o ressarcimento dos danos resultantes. $\mathrm{E}$, com estas palavras interpreta não só o pensamento do legislador mas também o dos estudiosos do assunto:

"Come è noto, la questione si presentò - e del resto tuttavia si presenta nel pensiero stesso del legislatore - come un aspetto o un momento del più ampio problema dei contratti preliminari, di quei contratti cioè che avrebbero per oggetto "la reciproca promessa di stipularne un altro fra le stesse parti". L'obbligo di contrarre sarebbe appunto l'oggetto e il contenuto specifico del contratto preliminare, ben distinto dall'oggetto del contratto da concludere. Posto ciò, parve a molti, ed anzi alla maggioranza degli studiosi, che un simile obbligo di contrarre fosse giuridicamente, e prima ancora naturalmente incoercibile, costituisse un facere infungibile, come quello che aveva radice nella libertà del volere, e anzi di questa libertà fosse la più tipica manifestazione. All'inadempimento di un obbligo di questo genere non poteva dunque seguire l'esecuzione specifica, ma soltanto il risarcimento dei danni”. Pg. 261.

Em face, porém, do que foi exarado no art. 2.932, o brilhante professor chega a declarar a desnecessidade de verificação da natureza e do conteúdo do contrato preliminar, a fim de se saber se o mesmo admite execução específica. Dada a feição autônoma, a própria fôrça do aludido contrato, perdeu o interêsse qualquer apreciação sôbre o elemento volicional, que seria necessário para a formação do contrato definitivo. Neste passo, êle assim se expressa:

"Oggi, la cosiddetta esecuzione specifica dell'obbligo di contrarre è consacrata da una norma di legge (art. 2.932). Comunque si voglia giudicare di que- 
sta norma, una cosa sembra certa: che l'impostazione tradizionale del nostro problema ne resulta assolutamente capavolta. Non si tratta più di stabilire la natura e il contenuto del contratto preliminare per decidere se esse ammette l'esecuzione specifica, bensì di stabilire quali conseguenze l'amissione dell'esecuzione specifica abbia sulla natura e suo contenuto del contratto preliminare.

E la prima conseguenza è che non si può più parlare di una prestazione di volontà come oggetto del contratto preliminare, di un obbligo di stipulare al quale corrisponda un diritto alla stipulazione, e quindi, in una parola, del contratto preliminare come di un contratto obbligatorio. La forza e il valore di tale contratto sta invece proprio in ciò: che per esso sorge il titolo per la costituzione di una situazione giuridica (finale), e precisamente della situazione giuridica determinabile in forza del contratto definitivo". (Pág. 262).

Finalmente, ao referir-se aos contratos, com efeitos reais, põe em relêvo a feição constitutiva da disposição legal comentada, salientando , nesse passo, a sujeição da parte obrigada, não a uma nova manifestação volitiva, mas aos efeitos decorrentes do próprio contrato. Neste particular, o ilustre mestre alude à promessa de venda, quando demonstra que quem promete vender um imóvel não promete uma volição futura mas quer, desde logo, a transferência do mesmo, no futuro.

E o que vemos neste excerpto de sua exposição:

"Il terreno di elezione dell'esecuzione specifica è quello dei contratti con effetti reali (art. 1.376), in primo luogo la vendita. E la ragione, dopo quanto abbiamo detto, ben si comprende: gli effetti reali non sono in funcione di un obbligo (di produrli), ma discendo direttamente dalla volontà dispositiva che si pone come una semplice condizione del loro prodursi. Ora la volontà dispositiva c'è tanto nella vendita quanto nella promessa di vendita (o di cos- 
tituzione di altro diritto reale): tale promessa non può quindi considerarsi come una promessa di volere (che sarebbe incoercibile) ma come una volontà dell'effetto, che non ha più bisogno di alcuna ulteriore volizione per il suo costituirse. Nasce dalla promessa il diritto alla costituzione dell'effetto (quando si saranno verificate le condizioni del transferimento), al quale non corrisponde un obbligo del promittente, ma una sua soggezione; e tale diritto sarà realizzato dal giudice, secondo il meccanismo proprio dei diritti cosiddetti potestativi. Così, ad es., se io prometto di vendere un immobile se questo mi sarà lasciato in eredità $o$ in legato, non prometto una mia futura volizione, ma voglio fin d'ora il futuro trasferimento. Potrò allora prestarmi o meno alla stipulazione del contratto di vendita, ma questo non impedirà che il diritto al trasferimento si realizzi". Pág. 263.

Em todo o caso, temos de concluir que as legislações que evolvem nesse sentido, como sucede com a nossa, ainda estão distantes da orientação seguida pelo Código Civil Francês, cujo art. 1589 declara:

"La promesse de vente vaut vente, lorsqui il y a consentment réciproque des deux parties sur la chose et sur le prix".

Realmente, essa equivalência não existe entre nós, porque, mesmo com a feição autônoma que a promessa ostenta nos últimos tempos, ela continua a ser um caminho para o contrato definitivo. Êsse caminho se tornou mais seguro, porém não se confunde com o fim a que conduz. $\mathrm{O}$ direito de prioridade para a aquisição da propriedade difere, na essência, e nos efeitos, do direito de domínio. 